(2)

\title{
Necrobiotic xanthogranuloma and chronic lymphocytic leukemia of the conjunctiva masquerading as scleritis and uveitis
}

This article was published in the following Dove Press journal:

Clinical Ophthalmology

6 December 2012

Number of times this article has been viewed

\author{
Amir Mohsenin' \\ John Sinard ${ }^{1,2}$ \\ John J Huang' \\ 'Department of Ophthalmology \\ and Visual Science, ${ }^{2}$ Department \\ of Pathology, Yale University School \\ of Medicine, New Haven, CT, USA
}

Correspondence: John J Huang Department of Ophthalmology and Visual Science, Yale University School of Medicine, 40 Temple Street, New Haven, CT 065 I0, USA

$\mathrm{Tel}+\mathrm{I} 2037852020$

Fax + I 2037855909

Email john.huang@yale.edu

\begin{abstract}
This report describes a unique case of coexisting necrobiotic xanthogranuloma and chronic lymphocytic leukemia in a patient presenting with scleritis and uveitis. A 53-year-old Caucasian man diagnosed with anterior uveitis and scleritis for the prior year was referred to our uveitis clinic for further evaluation. Prior uveitis/scleritis workup performed by the referring ophthalmologist was negative. Examination demonstrated unilateral uveitis and posterior scleritis along with bilateral conjunctival lesions. Incisional biopsy of the conjunctiva was carried out. The excised tissue was sent fresh for histopathologic studies. Slit-lamp examination revealed bilateral yellow-white bulbar conjunctival lesions, $1+$ conjunctival injection OU, stellate keratic precipitates OS with 25 cells per high-powered field. Funduscopic examination was significant for subretinal fluid OS. Conjunctival biopsy revealed necrobiotic xanthogranuloma and chronic lymphocytic leukemia. Systemic workup demonstrated paraproteinemia consistent with necrobiotic xanthogranuloma and a complete blood count consistent with leukemia. This case demonstrates an atypical presentation of necrobiotic xanthogranuloma and concomitant chronic lymphocytic leukemia presenting in the form of uveitis, scleritis, and conjunctival infiltration. Masquerade syndromes, such as necrobiotic xanthogranuloma and leukemia, must be kept in mind when treating patients with uveitis or scleritis with negative workups.
\end{abstract}

Keywords: necrobiotic xanthogranuloma, chronic lymphocytic leukemia, uveitis, scleritis, masquerade syndrome

\section{Introduction}

Masquerade syndromes are an important consideration in patients with refractory or atypical presentations of ocular inflammatory disease. Here we describe an unusual case of a patient referred for evaluation of uveitis and scleritis who was found to have intraocular and bilateral extraocular involvement of necrobiotic xanthogranuloma along with coexisting chronic lymphocytic leukemia (CLL).

\section{Case report}

A 53-year-old man was referred to our uveitis clinic for evaluation of iritis and scleritis in the left eye. The patient initially presented to his ophthalmologist 10 months earlier complaining of left eye pain and was treated for exacerbation of his existing dry eye syndrome. Three months later, he returned to his ophthalmologist with intermittent bilateral eye pain (left more than the right) and was found to have nongranulomatous anterior uveitis in the left eye with associated fine keratic precipitates as well as diffuse anterior scleritis. Laboratory workup and imaging was negative at that time and included a complete blood count, antinuclear antibody count, erythrocyte 
sedimentation rate, rheumatoid factor, anti-SSA, anti-SSB, lupus anticoagulant, antineutrophil cytoplasmic antibodies panel, and a chest $\mathrm{x}$-ray. He was started on oral prednisone, with resolution of his symptoms. After oral prednisone was tapered off, his symptoms returned, and he was then referred to our clinic for further evaluation. At presentation, visual acuity was 20/20 OU with intraocular pressures of $17 \mathrm{mmHg}$ OD and $15 \mathrm{mmHg}$ OS. Slit-lamp examination revealed mild injection of the left eye with stellate keratic precipitates and 25 cells per high-powered field. Bilateral yellow conjunctival lesions were seen temporally in the bulbar conjunctiva (Figure 1). Conjunctival biopsy was scheduled. At a subsequent follow-up visit shortly after initial examination, the patient presented with new onset of decreased vision in the left eye and was found to have subretinal fluid and leakage at the choroidal level (Figure 2). A second laboratory workup was ordered, including complete blood count, fluorescent treponemal antibody-absorption test, Lyme disease titers, erythrocyte sedimentation rate, C-reactive protein, angiotensin converting enzyme level, hepatitis panel, and liver function tests. Results were unremarkable except for a significantly elevated white cell count of 43.5 with $85 \%$ lymphocytes, an erythrocyte sedimentation rate of 42 , and a C-reactive protein of 27.5. The immunophenotype and morphological features of his peripheral blood smear were suggestive of atypical CLL. Bilateral conjunctival biopsies were performed and revealed necrobiotic xanthogranuloma (Figure 3) with an adjacent CLL component. Systemic chemotherapy was recommended.

\section{Discussion}

Necrobiotic xanthogranuloma is a rare progressive histiocytic disorder classically characterized by firm yellow plaques and nodules, most often found on the periorbital skin. There is a

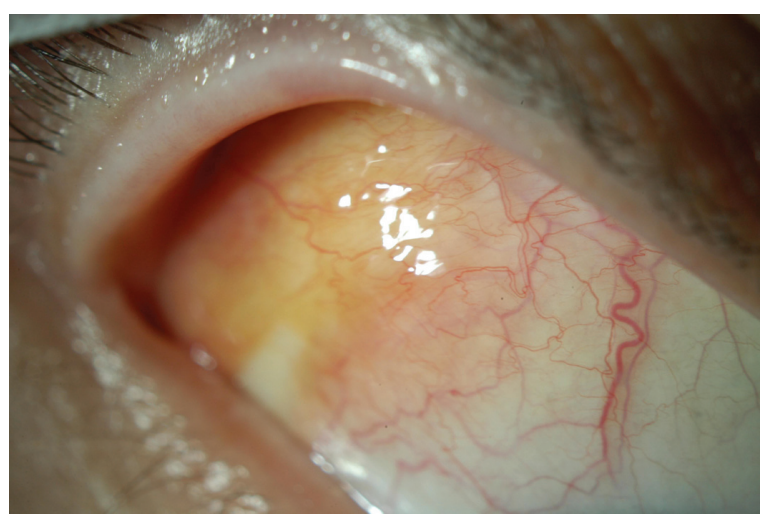

Figure I Bilateral yellow conjunctival lesions from necrobiotic xanthogranuloma and chronic lymphocytic leukemia.

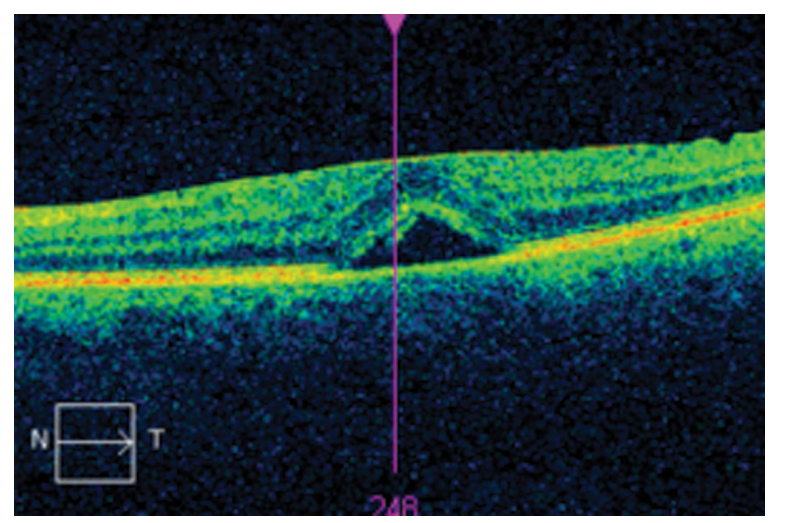

Figure 2 Optical coherence tomography demonstrating subretinal fluid in the left eye.

close association with paraproteinemia, and many patients have an IgG- $\kappa$ monoclonal gammopathy. Hematologic malignancy in patients with necrobiotic xanthogranuloma in the form of multiple myeloma, leukemia, and lymphoma has been reported. ${ }^{1,2}$ The pathogenesis of necrobiotic xanthogranuloma is not well understood, but Borrelia spirochetal infection has been proposed because organisms have been identified within the lesions. ${ }^{3}$ Others have hypothesized that there is enhanced monocyte phagocytic activity leading to lipid accumulation and a subsequent giant cell inflammatory response in the skin. ${ }^{4}$ The relationship between the hematologic abnormalities and skin lesions is not currently understood.

In one review of 48 cases of necrobiotic xanthogranuloma, ophthalmic complaints were reported in $50 \%$ of patients. ${ }^{5}$ Ocular manifestations of necrobiotic xanthogranuloma include decreased vision, burning, pain, proptosis, ptosis, diplopia, uveitis, episcleritis, and scleritis. ${ }^{2,6,7}$

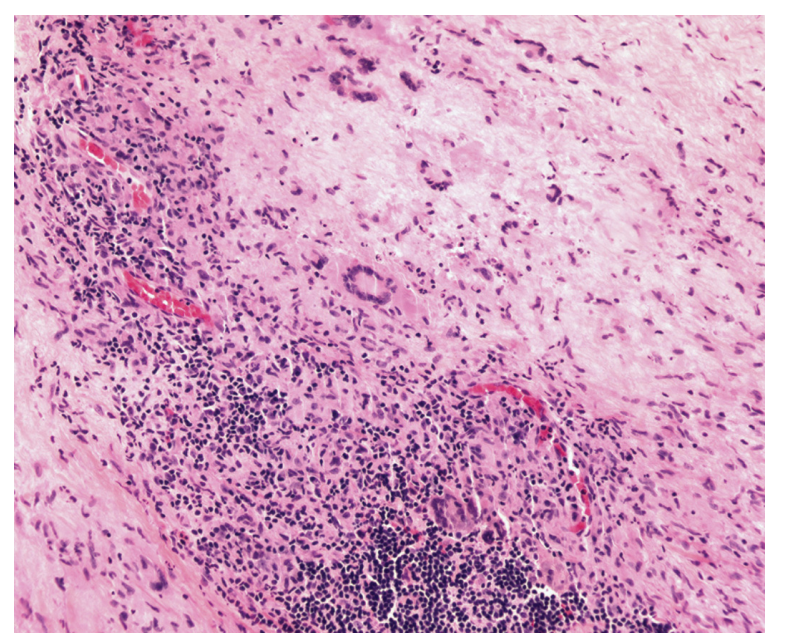

Figure 3 Hematoxylin and eosin stain of conjunctival biopsy demonstrating giant cells predominantly of the Touton type with leukemic cell infiltration of tissues. 
This case is unique because it is unusual for patients to develop ophthalmic manifestations of necrobiotic xanthogranuloma without the classic periorbital skin findings. Treatment of necrobiotic xanthogranuloma is primarily targeted at the skin lesions and various methods have been tried with inconsistent results largely due to our limited understanding of the disease process. Currently, the mainstays of treatment are systemic alkylating agents such as chlorambucil, cyclophosphamide, or melphalan given alone or in combination with systemic corticosteroids. Interestingly, systemic chemotherapy for concomitant hematologic malignancies does seem to have a beneficial effect on the skin lesions in a few reported cases. This case highlights the need to include masquerade syndromes, like necrobiotic xanthogranuloma and CLL, in the differential diagnosis of "idiopathic" uveitis or scleritis, especially when there are conjunctival or periocular skin lesions and an abnormal complete blood count.

\section{Disclosure}

The authors report no conflicts of interest in this work.

\section{References}

1. Oumeish OY, Oumeish I, Tarawneh M, Salman T, Sharaiha A. Necrobiotic xanthogranuloma associated with paraproteinemia and nonHodgkin's lymphoma developing into chronic lymphocytic leukemia: the first case reported in the literature and review of the literature. Int $J$ Dermatol. 2006;45(3):306-310.

2. Ugurlu S, Bartley GB, Gibson LE. Necrobiotic xanthogranuloma: longterm outcome of ocular and systemic involvement. Am J Ophthalmol. 2000;129(5):651-657.

3. Zelger B, Eisendle K, Mensing C. Detection of spirochetal microorganisms by focus-floating microscopy in necrobiotic xanthogranuloma. J Am Acad Dermatol. 2007;57(6):1026-1030.

4. Matsuura F, Yamashita S, Hirano K, et al. Activation of monocytes in vivo causes intracellular accumulation of lipoprotein-derived lipids and marked hypocholesterolemia - a possible pathogenesis of necrobiotic xanthogranuloma. Atherosclerosis. 1999;142:(2)355-365.

5. Mehregan DA, Winkelmann RK. Necrobiotic xanthogranuloma. Arch Dermatol. 1992;128(1):94-100.

6. Al-Bermani A, Figueiredo F, Speight EL, Jackson GH, Pandit R. Necrobiotic xanthogranuloma masquerading as posterior scleritis. Eye (Lond). 2009;23(1):239-240.

7. Robertson DM, Winkelmann RK. Ophthalmic features of necrobiotic xanthogranuloma with paraproteinemia. Am J Ophthalmol. 1984;97(2): $173-183$.
Clinical Ophthalmology

\section{Publish your work in this journal}

Clinical Ophthalmology is an international, peer-reviewed journal covering all subspecialties within ophthalmology. Key topics include: Optometry; Visual science; Pharmacology and drug therapy in eye diseases; Basic Sciences; Primary and Secondary eye care; Patient Safety and Quality of Care Improvements. This journal is indexed on

Submit your manuscript here: http://www.dovepress.com/clinical-ophthalmology-journal

\section{Dovepress}

PubMed Central and CAS, and is the official journal of The Society of Clinical Ophthalmology (SCO). The manuscript management system is completely online and includes a very quick and fair peer-review system, which is all easy to use. Visit http://www.dovepress.com/ testimonials.php to read real quotes from published authors. 